\title{
Humanistic Management and Living Wages: a Case of Compelling Connections?
}

\author{
Stuart C. Carr ${ }^{1}$. Jane Parker ${ }^{2}$. James Arrowsmith ${ }^{2}$. \\ Jarrod Haar $^{3} \cdot$ Harvey Jones ${ }^{4}$
}

Received: 1 August 2016 / Accepted: 22 December 2016 / Published online: 19 January 2017 (C) Springer International Publishing 2017

\begin{abstract}
The balance between employee pay and human thriving remains theoretically and empirically under-explored at the lower-end of the wage and income spectrum. Poverty Trap theory and the Law of Diminishing Returns offer seemingly contradictory predictions of the relationship between thriving and wages. An exploratory survey of low- and middleincome earners from a range of occupations was used to test these competing possibilities by relating hourly wage rates to thriving as measured by sense of (i) work happiness (job satisfaction, empowerment, and pride), (ii) well-being (mental and physical health, participation in community life, life satisfaction); and (iii) wage fairness (compared to upper management, reciprocity for the job). Linkages between pay and human capabilities (i)(iii) were statistically significant, and non-linear. Fairness (reciprocity) had the closest association with hourly wages and household income, suggesting a mediating role between pay and (i)-(ii). Increments in hourly pay yielded diminishing returns, whilst increments in household income only yielded clear gains, on feelings of pay justice, once the current campaigned-for living wage figure was breached. Poverty Traps and Diminishing Returns may each play a part in the link between on the one hand decent wages and income, and on the other hand eradication of working poverty.
\end{abstract}

Keywords Living wage · Poverty traps · Working poverty $\cdot$ Human capabilities · Decent work · Sustainable livelihood $\cdot$ Poverty eradication $\cdot$ SDGs $\cdot$ New Zealand

Stuart C. Carr

s.c.carr@massey.ac.nz

1 End Poverty \& Inequality Cluster (EPIC), School of Psychology, Massey University, Auckland, New Zealand

2 School of Management, Massey University, Auckland, New Zealand

3 Department of Management, Auckland University of Technology, Auckland, New Zealand

4 School of Psychology, Massey University, Palmerston North, New Zealand 


\section{Introduction}

\section{Aim and Purpose}

Work research can be criticized for acting as a "servant of power", serving the interests of management more than dignifying - humanistically empowering - labor by its focus and methods, including over-sampling from higher-income, upper management levels (Bergman and Jean 2015). Minimum Wages, which are macro-level legal protections, offer no protection to workers in the informal sector (International Labour Organization (ILO) 2016). They leave growing numbers of the formally employed in "working poverty" (Smith 2015). A recent global report strongly contends that "living" wages - meaning wage rates that enable a sense of dignified participation at work and in wider society - are vital for tackling poverty "in all its forms everywhere" (United Nations Development programme (UNDP) 2014; also Anker 2006). This study responds to these calls by aiming to address the empowerment of labor and working poverty (Carr et al. 2014). Its purpose is to test the possibility that there is a transformative living wage rate, or band, that boosts humanistic thriving, and thereby addresses both a gap in work research and a broader, more significant issue - the reduction of poverty and hardship.

\section{Theory}

At a purely theoretical level, it has been argued that living wages can contribute to humanistic thriving (Fox 2012) but only beyond a pivotal wage threshold for quality of living (Carr et al. 2016a). A sense of satisfaction with one's job and life, and increased perceived justice, are among the prominent humanistic indicators of thriving that a living wage could in theory enable (Fisher 2010).

Recent research has reported tentative signs of an income "pivot range" for such thriving (Carr et al. 2016b; Yao et al. 2016). Nonetheless, these initial analyses focused on different household income brackets rather than actual workplace wages, which would provide more correspondent and thereby definitive predictors of thriving at - and through - work (Ajzen 2011). Bracketing of household income may also mask nuances in the relationship between wages and humanistic thriving (e.g. an apparent spike in thriving across two income brackets may actually be a steep curve, which would only be seen using continuous scales on both variables). In the initial research, Carr et al. (2016b) used single rather than psychometrically reliable (when estimating curves) multi-item measures of thriving. In this paper, we instead use multi-item measures to explore whether there is a living hourly individual wage above which individual workplace thriving reliably pivots, in other words, an hourly wage point above which thriving progressively rises and below which it consistently either drops or stagnates.

\section{Ideology?}

The politics and practice of living wages is well rehearsed. The idea of Living Wages does not always appeal to government and business on the basis that it interferes with market mechanisms and increases costs in small firms and labour-intensive sectors in particular (e.g. The New Zealand Treasury 2013). However, to the extent that living wages create 'efficiency gains' in motivation and productivity and contribute to job stability (Stiglitz 1976), and job security rather than insecurity (ILO 2013), over time there may be offsetting benefits that reduce deleterious impacts in terms of employment costs and prices (Coulson and Bonner 2015). 
These range for instance from increased productivity and retention to work-life balance and worker wellbeing (Parker et al. 2016; to Haar et al. 2016). At the societal level, too, living wages may afford better social inclusion (Niedt et al. 1999) and help reduce poverty and the taxpayer burden of social transfers (Carr 2013; Carr et al. 2016b; Prowse and Fells 2015; Saner and Yiu 2012). However, much of the debate is speculative and dominated by orthodox economic theory and its assumption that driving wages ever downwards will paradoxically trickle up into job creation and wage growth for the working poor - something which for many has simply not happened (Cunniah 2012). An alternative approach, as yet untested as far as we can see, is to focus on the dynamics of the living wage through its potential impact on poverty traps and human "capabilities" (Sen 1999), in and through the workplace (Carr 2013).

\section{Anti-Poverty Capability}

As Lewin famously remarked, "there is nothing so practical as a good theory" (Lewin 1951, p. 169). One such useful theoretical concept associated with the living wage is that of a Poverty Trap (Carr et al. 2016a). Specifically, Poverty Trap theory claims that escaping from poverty is an all-or-nothing affair (Kraay and McKenzie 2014). Below a certain threshold, income today will always be less than income tomorrow; above the same threshold or cusp, income tomorrow will tend to exceed income today, that is, income mobility will pivot from negative (below threshold income) to positive when it rises above some critical income threshold (Banerjee and Duflo 2011). However, empirical findings of poverty traps, defined thus, have proved elusive, possibly as Kraay and McKenzie (2014) argue, in part because they do not take account of everyday human capabilities.

"Capability," in Sen's (1999) influential model, does not mean ability, or work competency, or capability in an everyday sense of 'doing' something on behalf of an employer. It is personfocused rather than task-centred. It differentiates between functionings and capabilities. The former can range from eating to being happy, whilst the latter means having the freedom to function in any way that people value - arguably a more meaningful criterion for human development out of poverty, including working poverty, than money alone (ILO 2013; World Bank 2014). Sen's (1999) model also includes the concept of agency. This means having the freedom to be an active, included and participating member of society - including at work. Under this view, money, wages and profit can be a means of enabling agency - and thereby people's functionings, and inherent capability to thrive. Agency is both means and end. As Sen (1999) observes, poverty "must be seen as the deprivation of basic capabilities rather than as lowness of incomes, which is the standard criterion of identification of poverty" (p. 87).

Nonetheless, under Sen's model, which is a cornerstone of the UN's (2015) Sustainable Development Goals (SDGs) for eradicating poverty, "inadequate income is a strong predisposing condition for an impoverished life [defined as] ... deprivations that are intrinsically important (unlike low income, which is only instrumentally significant" (1999, p. 87, parenthesis added).

Integrating the two theories of Poverty Trap and Human Capability enables the conceptual expansion of the theoretical foundations of living wages to include a "capability trap" (Lyneis and Sterman 2016). According to Sen's (1999) model, living wages are vital for people to escape from poverty traps, specifically by enabling them to function in ways that they inherently value (capabilities). First, at any given point in time, income and capability will be related non-linearly, with capability pivoting upwards only beyond a certain specific, yet-tobe-determined wage (above). Second, over the course of time, capability will become both end 
and means. Wages beget capability, which begets wage growth, and so on. Thus, escaping from any poverty trap is first and foremost about building not just wage mobility but more importantly building human capability (Sen 1999), that is, thriving (Carr 2013).

Which capabilities can living wages enable? Sen's (1999) proposition that money is an instrumental means to an end of thriving (above) logically infers that a decent income is one that boosts workers' sense of agency, for example, via a sense of empowerment (Alkire 2007). In the Humanistic Management literature, there are at least four grounds for such enablement (Spreitzer 1995): fostering a sense of meaning (which living wages might enable, Alkire 2008), self-efficacy (self-belief from earning a living per se, Alkire 2007), self-determination (a sense of independence at work and outside of it, Alkire 2002), and impact (through being entrusted with a decent wage, Carr et al. 2016a). Overall, a sense of empowerment has been found to be especially salient in lower-paid sectors such as services, and for lower-income levels generally (Seibert et al. 2011). Sense of empowerment was therefore measured in this study.

Empowerment is logically about redressing power imbalances and, in that sense, suggests that workplace justice will be an important humanistic benefit from a decent wage (Alkire 2007). According to the humanistic management literature, there are at least two senses in which pay levels can enhance sense of workplace justice and fairness (Furnham 2012; Seth and Alkire 2014): compared to fellow workers, for example, in a similar job or sector (Smith 2012); and compared to management and executives within the same employing organization (Carr 2010a, b; ILO 2013). Both absolute and relative wage levels are linked to perceived justice and fairness at work (Card et al. 2012; Mumford and Smith 2012). Absolute and relative indicators of thriving at work might therefore be respectively conceptualised as Reciprocity ("a fair day's work for a fair day's pay”) and as being informed by Upward Comparison, namely, comparing one's position on the pay ladder at work (Carr 2003; Harris et al. 2008). Remunerative justice may be especially salient at lower ends of the wage distribution, where it makes more of a noticeable difference (to quality of life, and work life) and is a more salient element in the psychological contract between employer and employee (Arrowsmith and Parker 2013; Coyle-Shapiro and Parzefall 2008; MacLachlan et al. 2012). Pay justice (reciprocity and upward comparison) was therefore measured in this study.

At the centre of workplace justice is the notion of enabling dignity in employment, for example, through being treated fairly, and with respect (Cohen-Charash and Spector 2001; Stiglitz 2002). According to the humanistic management literature, dignity fosters a sense of pride in, and identification with one's job, occupational role, and place at work (Jahoda 1982; Haslam 2004). Pathways for this sense of pride and identification to be fostered include, for instance, achieving a decent standard of living (Folger 1994), and having that achievement recognized by others (Carr 2004). Living wages are an organ of social and organizational inclusion (UNDP 2014). Occupational pride was thus measured.

Identifying with one's job - and being proud of that identity - implies that one is more rather than less likely to be satisfied with it. Satisfaction at work is often equated with happiness, which is a key human capability (Alkire 2002). Happiness at work, measured through the construct of job satisfaction, has enjoyed a resurgence of interest (Fisher 2010). Satisfaction with pay has been found to be a key element in satisfaction with the job (Spector 1997). Extant humanistic management research shows that job satisfaction levels are broadly influenced by wages (Judge et al. 2010; Marsella 1994). In itself, pay is often counted as an "extrinsic" satisfier or enabler of happiness, but it also has the potential to offer a sense of recognition and value for the skills one brings to a job and, in that sense, has "intrinsic," nonfinancial value (Stringer et al. 2011). Job satisfaction was therefore measured in this study. 
Perhaps the best-known way of operationalizing the relationship between wages and human thriving is via the humanistic criterion of well-being (Marsella 1994). Although insufficient in itself, money and in particular earning a decent, liveable income can enable a modicum of human happiness in everyday social life (Galinha et al. 2016). At least two, interconnected conduits for this happiness can be found in the humanistic management literature: 'at' work where wages can provide recognition of value, and 'outside' of work where they provide not only discretionary spending but may also relieve the pressure to work excessively long hours, thereby enabling 'work-life balance' (Haar and Brougham 2013; Haar et al. 2014). Constructs from happiness that are relevant in this humanistic work-family-life nexus would include both physical and emotional happiness, for example, through measures of occupational and/or life stress (Marsella 1994). A wider consideration of work-life balance would be the capability to enjoy a decent and dignified level of participation in community life, a capability that commonly forms part of defining a "living wage" (e.g. King and Waldegrave 2012; UNDP 2014). This kind of workplace-enabled thriving we might label Social Capability.

What kind of income-capability linkage exists? A theoretical function linking the above humanistic capabilities to workplace income in general, and to low versus living wages in particular, is shown in Fig. 1. The diagonal straight line represents the hypothetical case where a unit increase in income is matched by a unit increase in capability at any point 'in' time (today) and over any period 'of' time (tomorrow). Zero mobility is implied in either case. Extant studies of links between wages and job satisfaction (for instance) assume this kind of linear relationship (Judge et al. 2010). Against that baseline of fixed increments with each increment of income, the S-shaped (Sigmoidal) function in Fig. 1 would represent a capability poverty trap: capability never qualitatively transforms, say, from dissatisfaction to satisfaction, unless income itself reaches a critical "Living Wage Threshold". An example of 'backward movement' may be the individual who obtains a job only to then face increased financial demands but also stress as a result of having to buy new clothes, incur travelling costs (including time), eat out to socialise

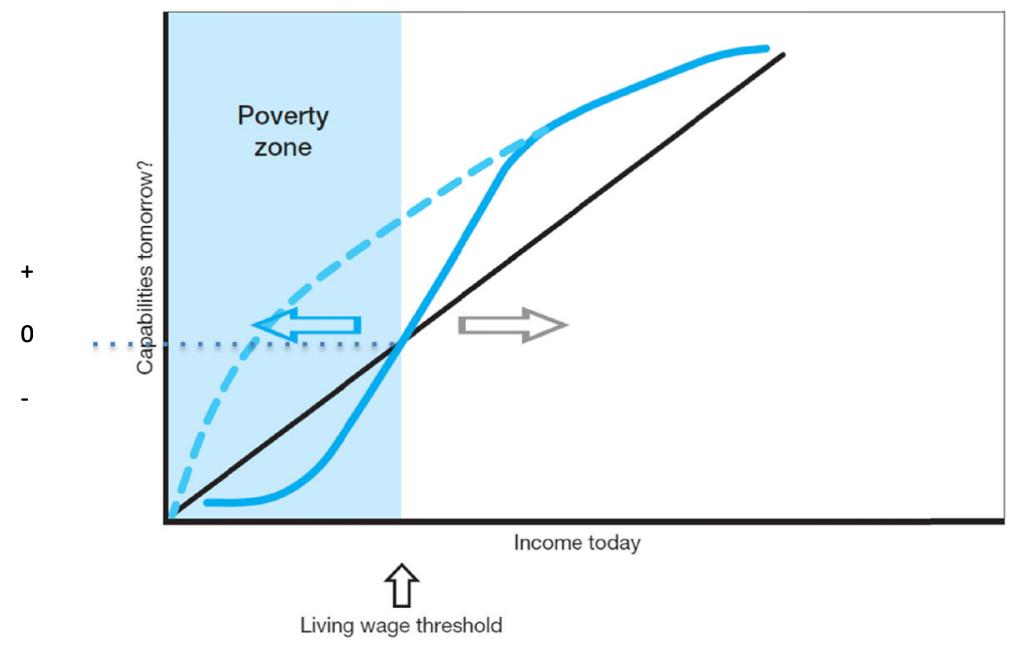

"Living wage threshold" is a theoretical range above which capabilities transform from negative to positive in valence, e.g., from job satisfaction to job dissatisfaction; and from life dissatisfaction to life satisfaction (below versus above the dotted line to $y$-axis).

Fig. 1 Capability as a function of wages. Source: Carr et al. (2016a, p. 10) 
with co-workers, and so forth. Alternatively, in a more directly workplace-related example, an employee may feel increasingly underpaid and undervalued, and hence become increasingly dissatisfied with, enslaved to, disempowered with, and disengaged from, his or her work.

Figure 1 also shows a competing hypothetical relationship between income today and capability tomorrow. Based on Bernouilli's Law of Diminishing Marginal Returns (Hastie 2010), the relationship between income today and capability tomorrow is likely not linear but logarithmic (Fig. 1, dashed line). To understand why, we need to consider that the intensity of any stimulus is a function of its baseline. For someone receiving a very low salary, an equal increment in wages will be much more noticeable, and likely appreciated, than that from a much higher baseline (Carr 2013; Hastie 2010).

This is potentially problematic for Living Wage campaigns because, according to the logarithmic curve in Fig. 1, the concept of a transformative living wage may be invalid - any pay rise will have a psychological impact on capabilities above the diagonal, and especially so at levels that are actually lower than a hypothetical - and possibly even illusionary - "living" wage (Carr et al. 2016a). From Fig. 1, the point or perhaps wage range where pay rate enables capability to cross from below (-) to above $(+)$ the proverbial waterline $(0)$, may thus be lower down the wage spectrum, in line with some critiques of the Living Wage (Carr et al. 2016b).

\section{Research Evidence}

If the concept of a living wage is not simple, neither is the practice of determining an actual hourly sum (Anker 2006, 2011). There is a paradox lurking in living wage research and practice. Living Wage figures refer to monies earned at the workplace but their meaning is felt, and certainly calculated for, both within the workplace and beyond - for instance, at the level of the household (Carr et al. 2016b). In practical terms, living wage figures tend to be calculated on the basis of costs of living for household units (Haushofer 2013; King and Waldegrave 2012, 2014). These, of course, vary a great deal in terms of size, income streams, dependents and other factors, and thereby in terms of need (Anker 2006). Representing that diversity by using the 'modal' or 'peak' family structure and configuration logically begs questions about the validity of the number for different family structures and configurations. In New Zealand, for instance (King and Waldegrave 2012, 2014), the use of a family unit with two adults, two children and 1.5 incomes (to allow for part-time childcare by one adult) has invariably led to criticisms that a single "Living Wage" figure cannot possibly be valid and representative for all homes and family units (The New Zealand Treasury 2013).

What does the twin context mean for research on living wages? In work psychology, the concepts of work-family and work-life balance remind us that, although these domains are interconnected, the nexus is by no means direct or unidirectional (Haar et al. 2014). According to Ajzen and Fishbein's (2005) principle of Correspondence/Compatibility in attitude-behavior research, the specificity of predictor variables (such as income at work) should always match bandwidth, that is, specificity of the criterion (in this case, capability at work, not at the wider household level). On average, according to Ajzen and Fishbein's (2005) seminal review of the attitude-behaviour linkage, circumstances at work will better predict behaviour at work (correspondence) than will circumstances at home and/or in the local wider community.

There are many reasons why income at work may predict capability at work but not necessarily at home for an entire household. For example, a wage earner may not share his or her wages equally, fairly or transparently amongst other household members (Sen 1999; World Bank 2014). Thus, if we rely solely on household income to detect income-work capability 
linkages, we are at risk of under-estimating or missing the link altogether (Type II error, or false negative). Fundamental measurement principles, as well as everyday household realities, demand that we measure income at work and capability at work, and the linkages between the two, before investigating any individual-to-household, that is, spill-over between work and family life in relation to capability at work.

A further issue for existing research on human capability and living wages concerns measurement reliability. The limited available research focusing on income and capability at work utilises single items and either stays focused at the household and not workplace level (Carr et al. 2016b) or has not been tested for fit to the identified competing functions in Fig. 1 (Carr et al. 2016b; Haushofer 2013). This study therefore utilised multi-item measures, focused on workplace pay and workplace capability, and performed initial (i.e. very much pre-modelling) curve estimates for linear, logarithmic and sigmoidal (S-shaped, on its side) functions. Our core research question is thus: is there a Living Wage that boosts human capability at work and (possibly) in society? Our core competing hypotheses are derived respectively from research on wages and job satisfaction (linear link) and from poverty trap theory versus diminishing marginal returns (sigmoidal versus logarithmic). These theories make the following competing predictions:

\section{Hypotheses}

$\mathrm{H}_{0}$ : Linear (i.e., we will observe the straight line in Fig. 1); vs.

$\mathrm{H}_{1}$ : Sigmoidal (i.e. we will observe the S-shaped curve in Fig. 1), versus.

$\mathrm{H}_{2}$ : Logarithmic (i.e., we will observe the dashed curve in Fig. 1).

\section{Method}

\section{Participants}

The country we sampled from was New Zealand (Carr et al. 2016b), which has been widely classified as a 'low wage economy' within the OECD (Kelly 2014). The statutory minimum wage rate is also relatively low at NZ\$14.75 in April 2015 (NZ\$15.25 from April 2016). The living wage campaign benchmark is now $30 \%$ higher than the legal Minimum Wage, having risen from NZ\$19.25 in 2015 to \$19.80 in July 2016 (Living Wage Movement Aotearoa New Zealand (LWMANZ) 2016). Participants were drawn from a wider, online mobile-assisted esurvey, WageingWell, with 1183 employees ( $n=68$ managers). Three-quarters of the sample were women (Carr et al. 2016b). However, although women may be over-represented in lower-income jobs, gender itself was not a significant covariate with respect to capabilities (Carr et al. 2016b). Thus we did not focus on gender as a variable.

We began with exploratory factor analysis of the capability measures (using pairwise deletion) utilising the total of $n_{1}=1183$ participants. The second part of the analysis involved relating selfreported hourly rates of pay to the factor scores, which reduced eligible participants to $n_{2}=266$. A Missing Values Analysis of the hourly rate question (predictor) and four capability factors (criterion variables) showed that, even though single items were used, the bulk of the missing data occurred on the pay measure $(64.7 \%)$ rather than the capability factors $(52.5 \%)$.

There are at least two reasons for the missing values to be distributed 'Not Completely at Random' (Little's MCAR test, Chi-Square $=56.867, \mathrm{df}=5, p<.001$ ). First, people are often reluctant to answer direct questions about their own pay (Carr et al. 2010). Second, and more 
fundamentally for this paper, people in lower-paid work (i.e. the focus in our analysis) are usually paid by the hour (hence the nomenclature of Living Wages, which are normally hourly rates) rather than by an annual salary (which may not be known or be incalculable because work is irregular). Only 232 participants answered both hourly rate and annual salary questions. The rest reported either hourly rate only $(n=217)$, annual salary only $(n=420)$ or neither $(n=404)$. Participants thus often chose one or the other. However, those who reported an hourly rate $(n=449$, mean $=\mathrm{NZ} \$ 26.44, \mathrm{SD}=21.19)$ were relatively low paid among the sample as a whole.

The drop in participation rate is understandable and indeed necessary given our analytical focus, but also underscores the exploratory nature of this research. Thus, although response rates on sensitive topics are notoriously low (Tourangeau and Yan 2007), we triangulated our exploratory probes of the linkages between hourly rate of pay and capability with an additional analysis of annual salary and capability. For a part-time or casual worker, for instance, annual salary may be more meaningful than hourly rates of pay.

\section{Procedure}

The questionnaire was developed in consultation with and piloted through a range of stakeholder groups including academics, labor unions, employers and management associations (Carr et al. 2016b). A key concern emerging from this process was to keep response burden minimal so as to elicit higher response, which meant using single items wherever possible. This meant that many existing measures - which rely on many items - could not be used. Furthermore, when developing an indicator of empowerment, we took considered advice that constructs like "locus of control" or "self-esteem", which feature in some models of empowerment (e.g. Spreitzer 1995), would apply more readily to management and professional roles rather than process-driven work. This meant that many existing measures that tend to have been developed with white-collar workers (Bergman and Jean 2015) could not be used. Instead, a deliberate decision was made, in line with survey practice, aligned with our intended samples, to tailor our measures to the respondents and roles we were seeking. This included using different scales for different measures, on advice from stakeholder constituents, including low-income employees (scores were standardized at the analysis phase, see Results). Following this heavily consultative piloting phase - necessary for buy-in from our respondent groups - the survey was publicised through a range of media and went 'live' from 1 October to 1 December 2014.

\section{Measures}

The pay question asked, "What is your (approximate) rate of pay (for your primary job)?" The present study focused first on reported Hourly Rate of Pay (a standard metric of Living Wages) rather than Annual Rate of Pay.

Work Capability was assessed by three items that the literature suggests are collectively indicative of work-related happiness (Fisher 2010; Sirota et al. 2005). Our focus on single-item global scales (such as for job satisfaction) reflects common practice with meta-analysis research (Wanous et al. 1997).

- Job satisfaction: We asked respondents "How satisfied are you with your primary job in general?" ( 1 = frowning face, $5=$ smiling face). According to Fisher $(2010)$, such icons are more effective than traditional Likert-type scales at capturing the affective components of job satisfaction; 
- Empowerment at work means employees feel that they have some control over how they do their work, and in workplace decisions that directly affect them personally. We asked respondents, in the light of this provided definition, "At work, how 'empowered' do you feel in general?" and invited them to "please move the bar under the speedometer, where $10=$ full empowerment and $0=$ zero", i.e., with no mid-point - this scale like the others was designed in consultation with labour, management and community stakeholder groups). This coding format was suggested through the consultative process, as was;

- Occupational pride: "How proud does your work make you feel?" (Reverse-coded to $1=$ frowning face, $6=$ smiling face).

Life Capability was assessed similarly to work capability, with four items collectively indicative of non-work-related happiness:

- Life satisfaction: "How satisfied are you with life in general?" (reverse coded to $1=$ frowning face, $6=$ smiling face);

- Physical well-being: "How would you rate your physical wellbeing?" ( 1 = frowning face, 5 = smiling face);

- Mental stress: "How would you rate your stress levels generally" $(1=$ frowning face, $5=$ smiling face); and

- Community participation: "What capability do you feel you have to live with dignity and to participate in normal community affairs, as active citizens in society?" ("Please move the bar under the [interactive] speedometer, where $10=$ full empowerment and $0=$ zero").

Wage justice was measured with nine items. One was a general question: "Overall, how fair would you say your wage is? ( 1 = thumbs down, 7 = thumbs up)"; another was "How satisfied are you with your pay?" ( 1 = frowning face, $5=$ smiling face $)$. The remaining items related to comparisons. We asked, "Do you think your wage is a "fair rate'?" for each of the following $($ coded Yes $=1$, Don't know/NA [Not applicable $]=0$, No $=-1$ )

- for the job;

- compared to your effort;

- compared to your qualifications;

- compared to similar jobs elsewhere;

- compared to the line supervisors in your organization;

- compared to the middle manager in your organization; and

- compared to the CEO [Chief Executive officer] in your organization.

The first four items related to a measure of Pay Fairness Reciprocity, while the last three related to a conventional multi-level measure of Upward Comparison (meaning the extent to which people compare their pay with fellow employees who are higher on the organizational pay scale).

\section{Results}

To endeavour to establish psychometrically reliable measures, we utilised Exploratory Factor Analysis (Principal Components) with oblique rotation given that there were no pre-specified restrictions on components extracted and to allow for inter-component correlation (Carr et al. 
Table 1 Exploratory factor analysis for capabilities

Principal components

\begin{tabular}{llll}
\hline $\begin{array}{l}\text { Pay fairness } \\
\text { reciprocity }\end{array}$ & $\begin{array}{l}\text { Work } \\
\text { capability }\end{array}$ & $\begin{array}{l}\text { Upward } \\
\text { comparison }\end{array}$ & $\begin{array}{l}\text { Social } \\
\text { capability }\end{array}$ \\
\hline
\end{tabular}

Fair rate for the Job

.861

Overall fairness of wage $\quad .838$

Satisfaction with pay $\quad .798$

Fair rate for qualifications $\quad .785$

Fair rate for effort $\quad .714$

Fair rate for versus elsewhere $\quad .634$

Occupational pride $\quad .869$

Job satisfaction $\quad .842$

Empowerment at work $\quad .670$

Fair rate versus:

Middle managers

CEO

Supervisor

Physical well-being

Mental stress

Life satisfied

Participation in community life

Eigenvalues

Percent Variance

Coefficients $\alpha$
.868

.809

.779

.874

.828

.635

.501

$\begin{array}{ll}1.32 & 1.13 \\ 8 \% & 7 \%\end{array}$

$.81 \quad .68$

Loadings $<.4$ have been suppressed. Pairwise deletion has been utilised on the raw data $(N=1273)$

2016a) (Table 1). The analysis produced a clear and interpretable four-factor solution, with no significant overlap via cross-loadings ( $>.4)$, and factor scores that by definition were standardized.

Reciprocity in pay and Upward Comparison in pay were inter-correlated (.47) as (to be expected) Work and Social Capabilities (.40). Coefficient Alpha $(\alpha)$ ranged within acceptable values for the relatively small number of items per component (.67-.89) ${ }^{1}$. The Principal Components form of factor solution (Table 1) explained two-thirds of the variance.

We therefore utilized these standardized factor scores for the next phase of our study exploratory curve estimation. To enable sigmoidal curve fitting, which requires positive numbers, a constant of +4 was added to factor scores saved from Principal Components Analysis such that the scoring became +1 to +7 , with 4 the new mid-point ( $\mathrm{z}$-score $=0$, sample mean).

\section{Curve Estimations}

Given our focus on lower-incomes and capabilities, we screened for outliers at the upper but not lower end of the hourly wage and capabilities ranges. This revealed five cases of hourly pay in excess of NZ $\$ 100$ per hour which were removed from the analysis, leaving a curve estimation sample of $n_{2}=266$. Next, we conducted visual scans of scatterplots and regression curve analyses on the following types of relationship between hourly rates and capabilities: linear, logarithmic and sigmoidal (S-shaped) functions. Our most basic concern was exploring whether the link between hourly rate and capabilities was linear or non-linear (i.e. polynomial).

\footnotetext{
${ }^{1}$ Alpha tends to reduce when the number of items is low, even though a scale may be internally quite consistent/ reliable.
} 
To this end, we utilised a combination of curve estimation plots and plots of residuals from the linear regression. Any pattern or "bias" in the latter signifies that linear regression is not sufficient to explain the data, that is, that polynomial curve estimation is required. Initial inspections of the plots for single items suggested the possibility in addition to logarithmic and sigmoidal relationships, of a cubic function (which can be an S, inverted S or inverted Lshape). We therefore included polynomial cubic regression in our initial tests of the relationship between hourly rate and subjective, human capability.

The regression analyses are summarized in Table 2 . They are organized in descending order from amount of variance explained. Reciprocity is clearly the most accurately predicted criterion variable (29\%), whilst pay fairness in comparison with upper management was least well predicted $(5 \%)$.

From Table 2, for each dependent variable, the linear function was statistically significant but explained noticeably less variance than its non-linear counterparts. Between these nonlinear functions in turn, logarithmic functions tended to be less informative than either cubic or $\mathrm{S}$-shaped curve estimations. Whilst cubic regression consistently explained more variance in the criterion variables than its logarithmic counterpart, there was from Table 2 no compellingly obvious difference to enable a confident choice between them. Moreover, the shape of the cubic functions themselves varied, between inverted S ("Cubic-Bézier") to S-shaped (for Upward Comparison). Apart from demonstrating non-linearity therefore, these initial curve estimations were inconclusive.

One possible reason for the lack of definitive patterns was the presence of salient covariates, which curve estimations (in SPSS) do not allow to be included. To probe their potential further, we utilized Multiple Analysis of Covariance (MANOCOVA) which enabled statistical control for potentially informative covariates, including full-/part-time employment, number of people in the household, children in the household, number of household incomes, number of fulltime incomes in the household, and number of other dependent adults in the household.

The dependent variables were the factor scores for capability. The predictor variable was hourly wage coded into brackets ${ }^{2}$ of $\mathrm{NZ} \$ 4.00$, starting from NZ\$6.01-\$10.00 inclusive, up to maximum $=\$ N Z 86.50$. With the exception of the second lowest category, the $n$ 's for each of the wage brackets were all greater than the number of variables and included $n=76$ and $n=62$ for the two Wage brackets straddling the then Living Wage.

The sole covariate to demonstrate any covariance with our capabilities as a set was the number of dependents in the household other than children $\left(F_{4,563}=3.081, p=.016\right.$, Partial Eta-squared $=.021)$. Other than this small but statistically inverse relationship with reciprocity and upward comparison, household composition factors were not salient predictors of our four main capabilities. In contrast, there was a clear significant multivariate effect of wage bracket on capabilities as a set $\left(F_{36,2111}=4663, p<.001\right.$, partial Eta-Squared $\left.=.072\right)$. The effect of hourly wages on capabilities was consistent across all four: reciprocity $(F=14.693, p<.001$, partial Eta-squared $=.189)$; work capability $\left(F_{9,566}=6.354, p<.001\right.$, partial Etasquared $=.092)$; life capability $(F=3.501, p<.001$, partial Eta-squared $=.053)$; and upward comparison $(F=3.531, p<.001$, partial Eta-squared $=.053)$.

We next sought to determine at what dollar point(s) fixed increments in hourly pay were linked to upwards inflexion(s) on each of the human capabilities measured.

\footnotetext{
${ }^{2}$ We critiqued brackets earlier on the grounds that they may mask either curves or pivots. However, the core issue here is whether the covariates played any role in the relationship, not its precise shape.
} 
Table 2 Fit statistics for curve estimations

\begin{tabular}{|c|c|c|c|c|c|}
\hline \multirow[t]{2}{*}{ Capability:- } & \multicolumn{5}{|c|}{ Model Summary } \\
\hline & $R$ Square & $F$ & df 1 & df 2 & Sig. \\
\hline \multicolumn{6}{|l|}{ Reciprocity } \\
\hline inear & .19 & 61.9 & 1 & 264 & .000 \\
\hline Logarithmic & .25 & 88.0 & 1 & 264 & .000 \\
\hline Sigmoidal & .28 & 104.1 & 1 & 264 & .000 \\
\hline Cubic & .29 & 35.1 & 3 & 262 & .000 \\
\hline \multicolumn{6}{|l|}{ Work capability } \\
\hline Linear & .06 & 16.0 & 1 & 264 & .000 \\
\hline Logarithmic & .07 & 20.8 & 1 & 264 & .000 \\
\hline Sigmoidal & .06 & 16.1 & 1 & 264 & .000 \\
\hline Cubic & .09 & 8.6 & 3 & 262 & .000 \\
\hline \multicolumn{6}{|l|}{ Life capability } \\
\hline Linear & .03 & 8.2 & 1 & 264 & .005 \\
\hline Logarithmic & .04 & 11.9 & 1 & 264 & .001 \\
\hline Sigmoidal & .05 & 12.7 & 1 & 264 & .000 \\
\hline Cubic & .06 & 5.3 & 3 & 262 & .002 \\
\hline \multicolumn{6}{|c|}{ Upward comparison } \\
\hline Linear & .04 & 11.4 & 1 & 264 & .001 \\
\hline Logarithmic & .04 & 12.1 & 1 & 264 & .001 \\
\hline Sigmoidal & .03 & 8.3 & 1 & 264 & .004 \\
\hline Cubic & .05 & 4.8 & 3 & 262 & .003 \\
\hline
\end{tabular}

The independent variable was: "If you don’t mind us asking, what is your (approximate) rate of pay (for your primary job)?” (Rate of pay: \$/hour)

Post hoc LSD (Least Significant Difference) tests were conducted across each wage bracket, for each of the four main capabilities in Table $1 .^{3}$ These enabled us to determine not just visually but statistically where cutoff points were reached.

On Reciprocity, the first statistically significant spike occurred across NZ\$14.01-\$18.00 versus NZ18.01-\$22.00 per hour $(p<.001)$. There, mean factor scores climbed relatively sharply from 3.061 to 3.870 . There were also additional significant, lower-in-magnitude increases in reciprocity between NZ\$18.01-\$22.00 versus NZ\$26.01-\$30.00 $(p=.018)$ and between NZ\$22.01-\$26.00 versus NZ\$26.01-\$30.00 ( $p=.036)$. Multi steps like these are more suggestive of the increasingly shallower inverted L than Sigmoidal function in Fig. 1.

On Work Capability, there was a significant spike from NZ\$14.01-\$18.00 versus NZ\$18.01-\$22.00 $(p<.001)$ and across no other bracket thereafter. After correcting for the significant covariate, the mean capability scores respectively were 3.313 versus 4.045 . By straddling a transformed factor score of 4 (a factor score of 0 is a $\mathrm{z}$-score of 0 , which is the sample mean), capabilities went from below to above-average for the sample as a whole, as hourly rate straddled the then living wage rate $(\mathrm{NZ} \$ 18.80)$. Nonetheless, to the extent that an Sshape required a period of 'flat-lining' before climbing significantly, the observation of a single and relatively immediate significant climb suggested more the inverted L than $\mathrm{S}$ in Fig. 1.

On Life Capability, again there was a sharp increase from NZ14.01-\$18.00 versus NZ\$18.01-\$22.00 $(p<.001)$. Mean factor scores went from 3.511 to 4.199 , that is, once more straddled below versus above the average for the sample in Table 1, on this capability. Again

\footnotetext{
${ }^{3}$ There were just $n=4$ participants in the wage bracket NZ\$10.01-\$14.00 inclusive. Unsurprisingly, we detected no significant differences between any of the capabilities reported in this wage bracket compared to the others.
} 
too, there were no further significant increases in life capability across any other wage band. The emergent pattern so far was thus more consistent with inverted L than S.

On Upward Comparison, the pattern changed. From NZ\$14.01-\$18.00 versus NZ\$18.01-\$22.00, there was no significant increase in perceived fairness with upper management pay. The curve was relatively flat during this interval: mean scores on upward comparison rose only from 3.594 to 3.794 , which are both below the average for the sample as a whole (Table 1). Only thereafter came the first statistically-significant improvement in perceived upward comparison fairness, across two brackets of between NZ\$14.01-\$18.00 versus NZ\$22.01-\$26.00 ( $p=.009)$. In this relatively wide interval, which further implies flatness in the function, mean factor scores climbed from 3.594 to 4.137 , that is, they crossed a factor score of 4 (which was originally zero, above). Zero means a $z$-score of 0 (i.e. the sample mean in Table 1). Post hoc, across the three upward comparison items in Table 1, mean raw score per item was -0.11 , on a scale that ranged from -1 to +1 . Responses thus went from negative (unfair) to positive (fair) in valence, that is from '-' through ' 0 ,' to ' + ,' in Fig. 1. Thereafter, there were further significant, albeit lesser increases between NZ\$18.01-\$22.00 versus NZ\$38.01-\$42.00 $(p=.023)$ and NZ\$26.01-\$30.00 versus NZ\$38.01-\$42.00 $(p=.031)$. Overall, therefore, the data for upward comparison were partly consistent with, and to that extent suggestive of, an S-shaped capability trap.

In order to explore these nuances in more empirical detail, we plotted the linkages between hourly pay and each capability (Figs. 2, 3, 4 and 5). The Figs. 2, 3, 4 and 5 clearly show clusters of data points, suggesting that a curved function may not be sufficiently supple to thread through them. Instead, we utilized LOESS (for LOcal regrESSion) analysis (Cleveland and Devlin 1988). As the name suggests, LOESS is an exploratory technique that provides flexibility to probe potentially different curvatures for adjacent, different segments within the same dataset (e.g. pivot points, cusps, points of inflection, any other sharp changes in any function). The results of these LOESS analyses are included in Figs. 2, 3, 4 and 5. Because LOESS can be strongly influenced by unusual observations (Jacoby 2000), we removed a further three, noticeable outliers from the lower end of the sampled wage continuum (NZ\$6.82, NZ\$10.00 and NZ12.00 per hour). In Figs. 2, 3, 4 and 5 (with tension parameter $\alpha=.50$ ) the functions were neither overly smoothed nor jagged (Jacoby 2000), $k=$ Epanechnikov ${ }^{4}$ ).

Taken together, Figs. 2, 3 and 4 indicate that the link between hourly pay with Work and Life Capabilities tends to more closely resemble the dashed than blue arc in Fig. 1. A potential exception to this pattern is Upward Comparison. From Fig. 5, there was a distinctive scallop shape, resembling the lower half of the continuous blue line in Fig. 1. Figure 5 contains visible clusters of data-points either side of even a localized regression line. Wanting to be more confident in any potential inference of a scallop, we probed linkages between household annual rather than just workplace hourly rate and capability.

First, we removed seven clear outliers with annual salaries that exceeded NZ\$200,000. There were no evident outliers at the lower end of the salary spectrum. We then plotted the linkages between each of the four capabilities and conducted LOESS regressions $(n=399)$.

Unlike the regression lines for work and life capability, which were almost flat (i.e. no relationship), the slopes for fairness, both reciprocity and upward comparison, trended upwards (Figs. 6 and 7). On these workplace justice variables, from Figs. 6 and 7, there was a much clearer resemblance to the solid blue S-shaped function in Fig. 1 (a capability trap).

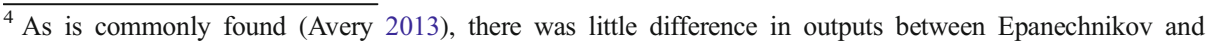
alternative kernel methods.
} 


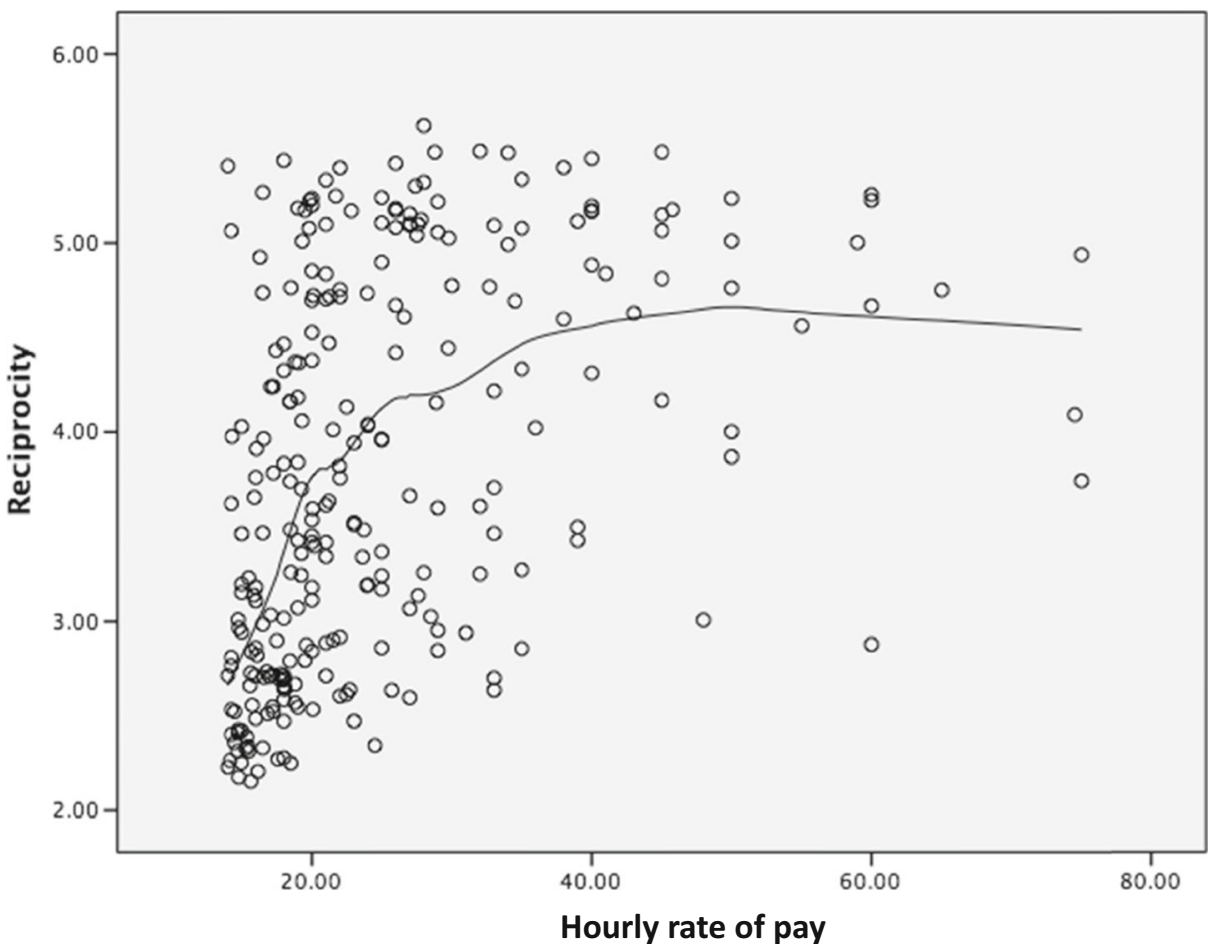

Fig. 2 LOESS curve for reciprocity as a function of hourly pay

Specifically, in Figs. 6 and 7, capability was clearly flat through the low spectrum of household income. Indeed, it only started to climb during a pivotal range somewhere between $\mathrm{NZ} \$ 30,000-\mathrm{NZ} \$ 50,000$ per annum.

\section{Discussion}

\section{Summary of Findings}

Our primary purpose was to probe the relationship of hourly wages (rather than household income) to work and non-work capabilities, and thereby explore the relevance of the living wage concept in terms of work-related human thriving. We found a relatively stable pattern in the relationship between hourly pay and quality of life and work life. Importantly, the shape was not simply linear (Judge et al. 2010). The relationship between hourly pay and measures of human capability, both at work and in wider society, was consistently curvilinear. This is important because many studies of pay and work attitudes assume linearity, and may thus be under-estimating the true linkages between income and capability.

The predominant shape of curve found when applying curve estimation was an inverted S-shape, in which capabilities tended to rise more steeply at the lower end of the income curve - suggesting diminishing marginal returns - before pausing and rising again (risepause-rise). The pause occurred just above the campaign Living Wage across New Zealand 


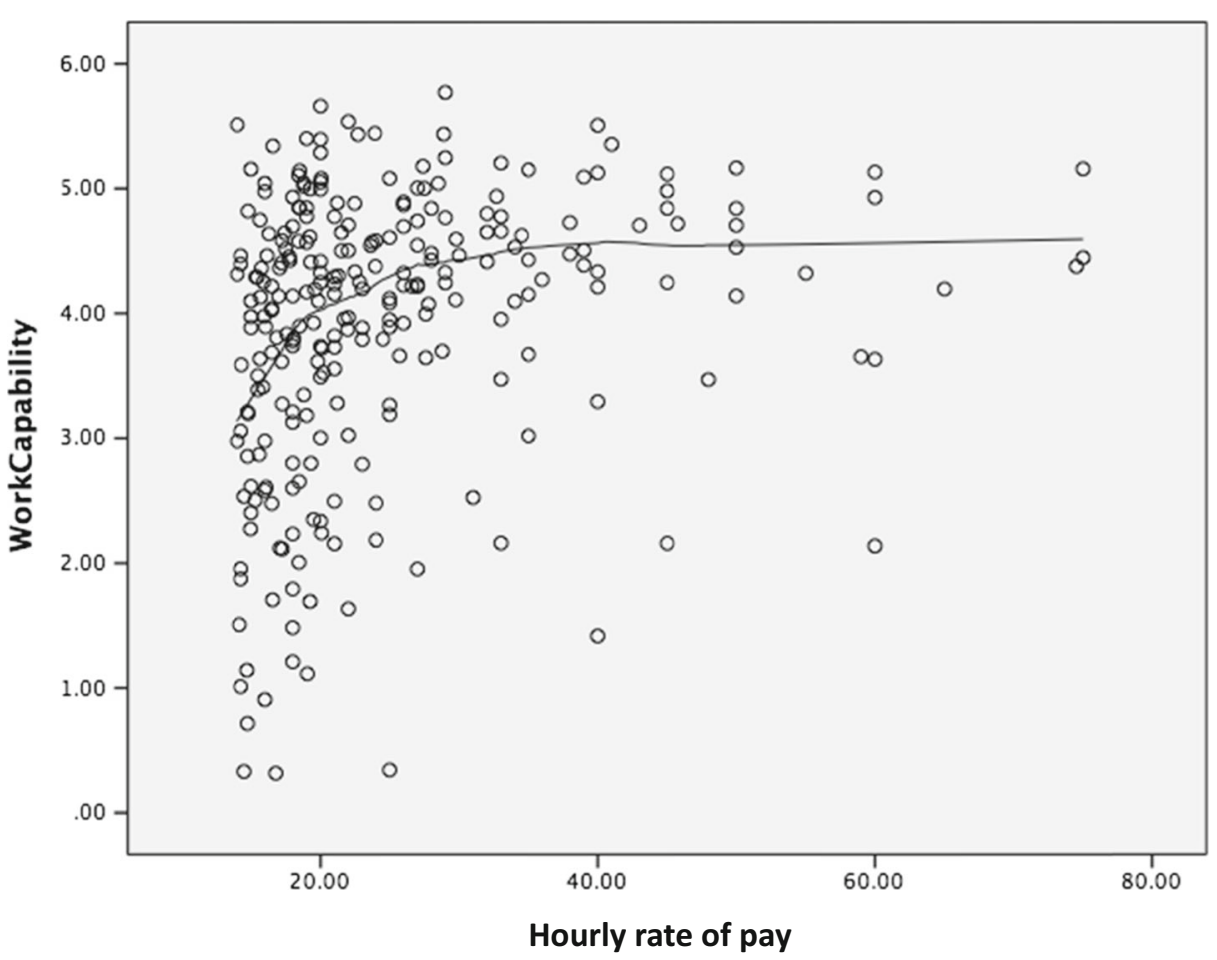

Fig. 3 LOESS curve for work capability as function of hourly pay

at the time ( $\approx \mathrm{NZ} \$ 20 /$ hour). Controlling statistically for variables such as number of dependents and types of income, we corroborated this pattern. LOESS curves then indicated a possibly more differentiated pattern. For work and life capabilities, and for reciprocity at work, we again observed a diminishing marginal return on cross-sectional wage increases. For upward comparison the shape was a more equivocal double-scallop, with clusters of residuals (Fig. 5).

A subsequent crosscheck using annual salary found a different pattern. Household income did not predict individual work capability or life capability (above, Ajzen 2011). Nonetheless, for work justice there was a linkage. Increments at the lower-end of the pay spectrum were NOT apparently linked to benefits in perceived wage fairness, compared to management, UNTIL the wage itself had passed a certain pivotal rang, in this case somewhere between NZ\$ 30-50 K per annum (Figs. 6 and 7). Coincidentally (or not), again this threshold was close to the campaign living wage rate in New Zealand at the time of the study (NZ\$18.80). Moreover, the pattern suggests a poverty trap (the Sigmoidal function, Fig. 1).

\section{Synthesis}

Taken as a whole, these findings imply a combination of 'think hourly pay - think diminishing returns,' alongside 'think household income - think trapped in pay injustice.' For example, if household income is not enough to compensate for a low personal hourly wage, then one may feel unfairly caught in low pay unfairness. Indeed pay injustice, because of its relatively close link with pay, may be a central, possibly mediating human factor in determining humanistic wage policies (Bosse and Phillips 2016). 


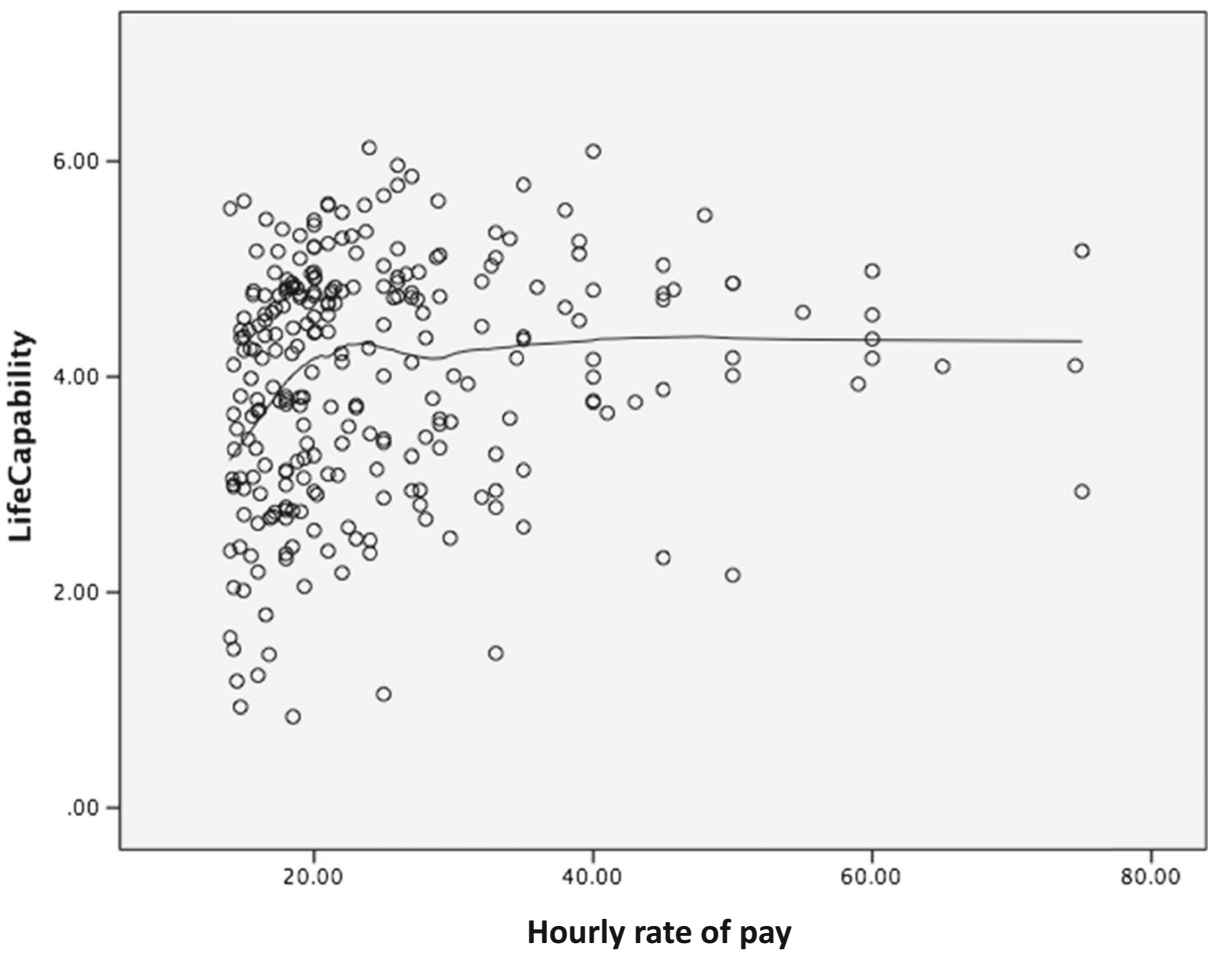

Fig. 4 LOESS curve for life capability as a function of hourly pay

\section{Improvements and Future Directions}

There are several ways in which this exploratory research could in future be improved.

First, we need to confirm the factor structure and measurement model in Table 1. We also need to include more variables in a structural model.

One example would be intra-organizational inequality (ILO 2013). Level of executive compensation (which we have just seen is no different, in comparative terms, to compensation for more proximal managers) may have profound effects on perceived work justice on the shop floor in the same organization (Cobb 2016). Future research should measure the level of income inequality within a workplace, or employing organization, for instance, using an "Organizational Gini Coefficient" (Carr \& Gini 2011, p. 102). Comparative workplace income may be a more salient and thus better predictor of job and life satisfaction than objective income (Galinha et al. 2016).

Such gains might conceivably work for both employees and employers (Card and Krueger 1994). Perceived fairness in pay, for example, has been linked to efficiency gains and workforce retention (Cohen-Charash and Spector 2001; Colquitt et al. 2001). So too have job satisfaction (Fisher 2010; Latham et al. 2002), workplace empowerment (Seibert et al. 2011) and occupational pride (Niedt et al. 1999; Van Knippenburg 2000). More latterly, perceived fairness in pay determination itself has been linked to occupational health and workforce wellbeing (Leineweber et al. 2016). Organizational commitment and engagement may also provide acceptable proxy measures for organizational efficiencies (Kuvaas 2006). 


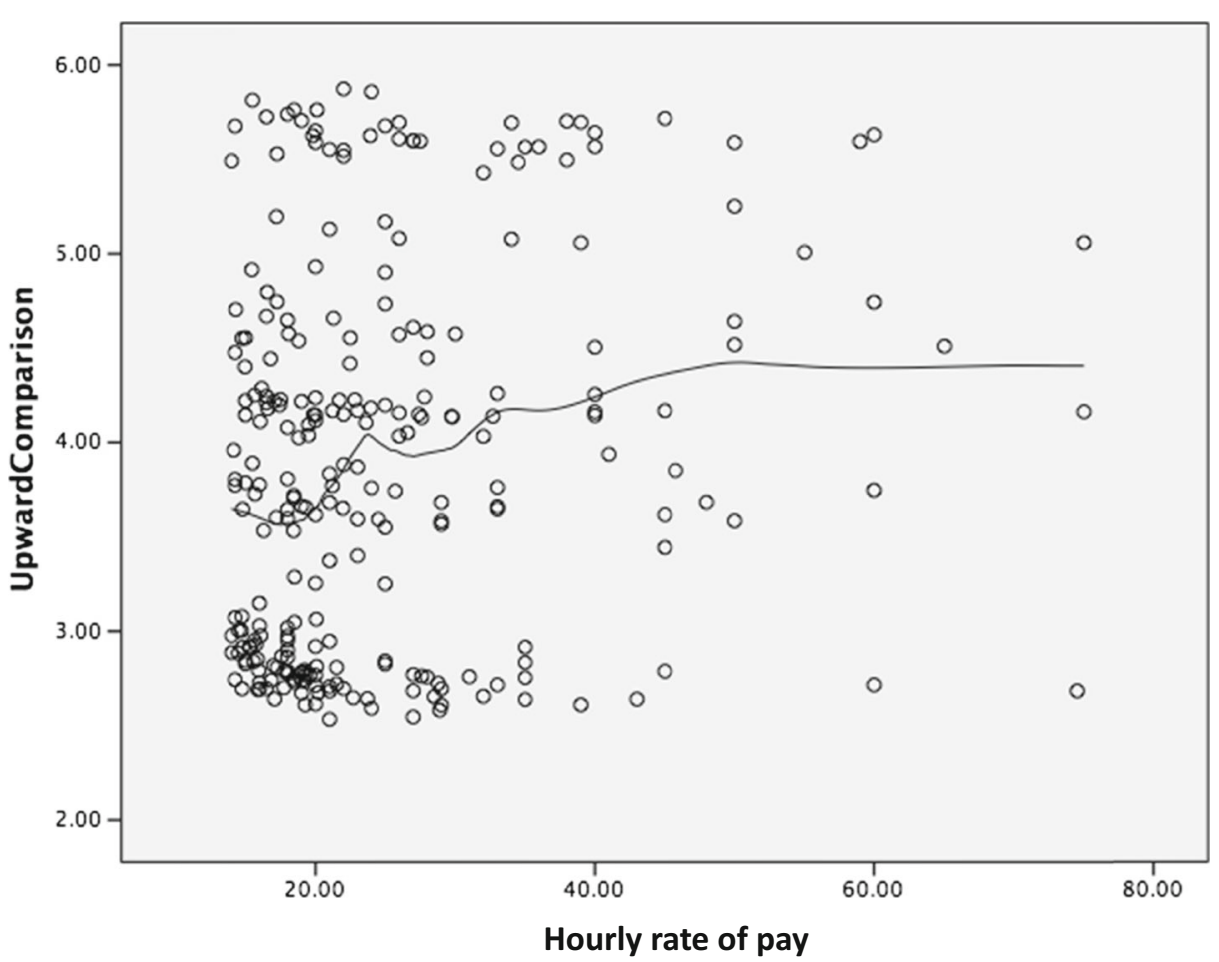

Fig. 5 LOESS curve for upward comparison as a function of hourly pay

Potential mechanisms for efficiency gains from living wages, involving capabilities, are implied by Sen (1999) who stated that "enhanced capabilities in leading a [working] life would tend, typically, to expand a person's ability to be more productive and earn a higher income, [and] we would also expect a connection going from capability improvement to greater earning power and not only the other way around" (p. 90). As such, after an initial boost from living wages, we would expect positive income mobility over time (Fig. 1). Alternatively, the links between wages and thriving may be fixed and immutable, fundamentally "locked-in" to a cross-sectional rather than dynamical relationship (Arthur 1989). Our study provides a crosssectional baseline from which these intriguing competing possibilities can be tested, through longitudinal study (Haar et al. 2016).

In that respect, there is a range of testable propositions for future research. For example, organizations that pay perceived fair wages at Time 1 in Fig. 1 may boost workplace capabilities at Time 2; (time is a level 2 moderator - interactive effect). Organizations that pay fair wages at Time 1 may boost social capabilities at Time 2; (time is a level 2 moderator - interactive effect). Workplace fairness at Time 2 may mediate between living wages at Time 1 and (a) productivity, (b), innovation, (c) organizational citizenship behavior and (d) retention at Time 3. Workplace wage fairness could mediate between capabilities like job satisfaction/empowerment/pride and (a)-(d). Customer patronage might also mediate living wages and profitability (e.g. via reputation and brand promotion). Indeed, all of the above might apply inter-organizationally, that is, through benchmarking and across supply chains. Fair wages could also potentially make more of a difference in capability enablement to socially disadvantaged minorities. Shared prosperity and thriving 


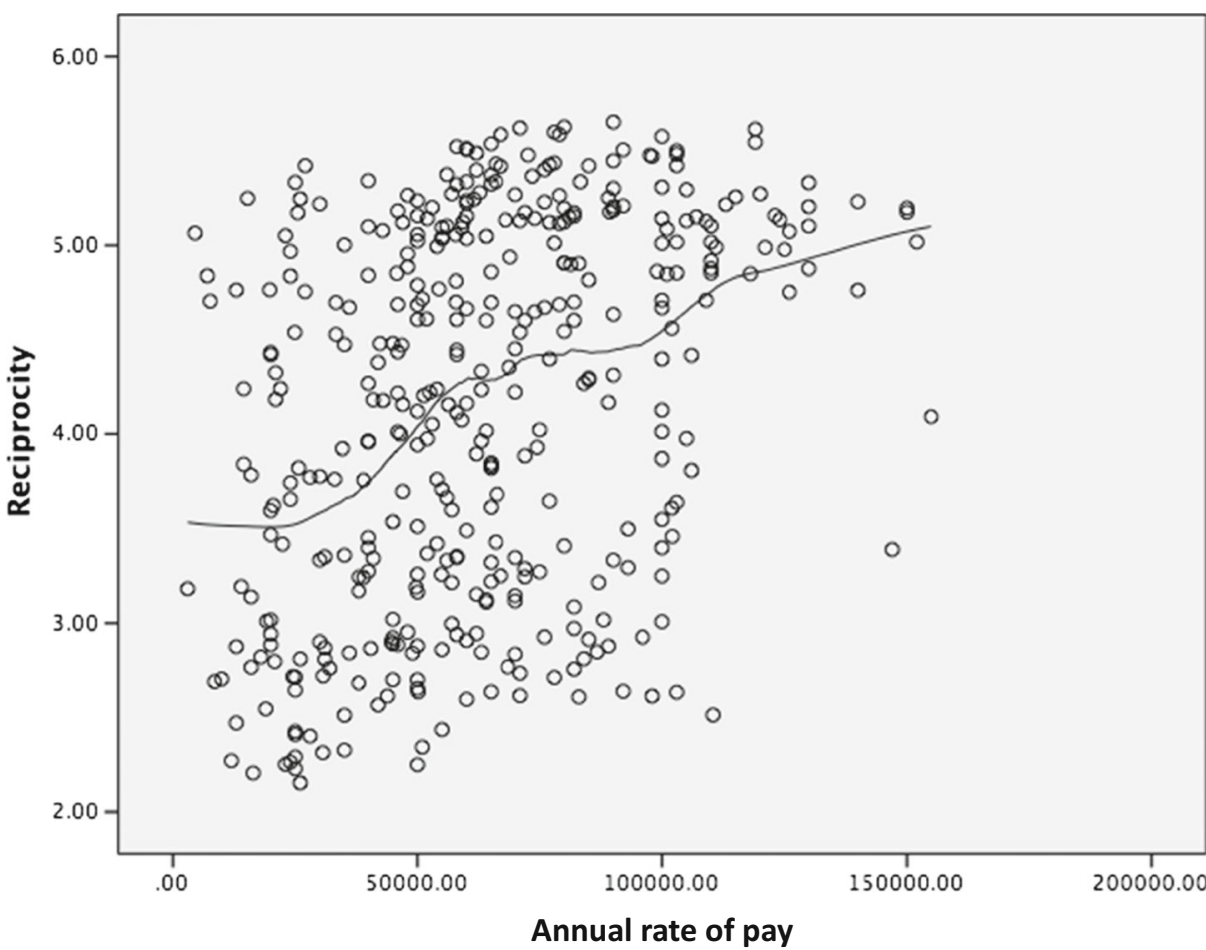

Fig. 6 LOESS curve for reciprocity as a function of annual salary. Note: Tension parameter adjusted from .50 (default) to .35

is not always a question of socio-economic divides: "When the poor are from one race, ethnicity, or region, and the rich are from another, a lethal, destabilizing dynamic often emerges" (Doyle and Stiglitz 2014, p. 4). Future research may therefore include questions about ethnic self-identification.

Finally, this study unexpectedly found links to the campaign Living Wage rate in New Zealand (NZ\$18.80 at the time of this study). These rates tend often to be estimated econometrically, for instance by using household surveys to extrapolate an hourly rate required by an average (and arguably often fictitious) household configuration. At no point is the human being directly consulted about the meaning of living on differing levels of income, in terms of subjective quality of life, and work life. Our study arguably breaks new ground in this direction, not only by asking people directly, but also by calibrating the links between incomes on the one hand and quality of (work) life on the other. When we did this, we found that the question of living wages is more complex than at first sight.

Ultimately, we suggest that this kind of research behooves humanistic management researchers worldwide to extend management consideration of the pay ranges leftwards along the $x$-axis in Figs. 2, 3, 4 and 5, so that we reach the World Bank's threshold for "extreme" poverty, that is, Purchasing power parity of $\leq \$ 1.90$ per day (World Bank 2016). With our particular sample (who had access to computer technology), we may have only begun to scratch the surface of many non-simple relationships between money and surviving-vs.-thriving at very low ends of the income spectrum. Conceivably for example, the curves in Fig. 1 may fuse together (dotted line moves upwards and rightwards to merge with 


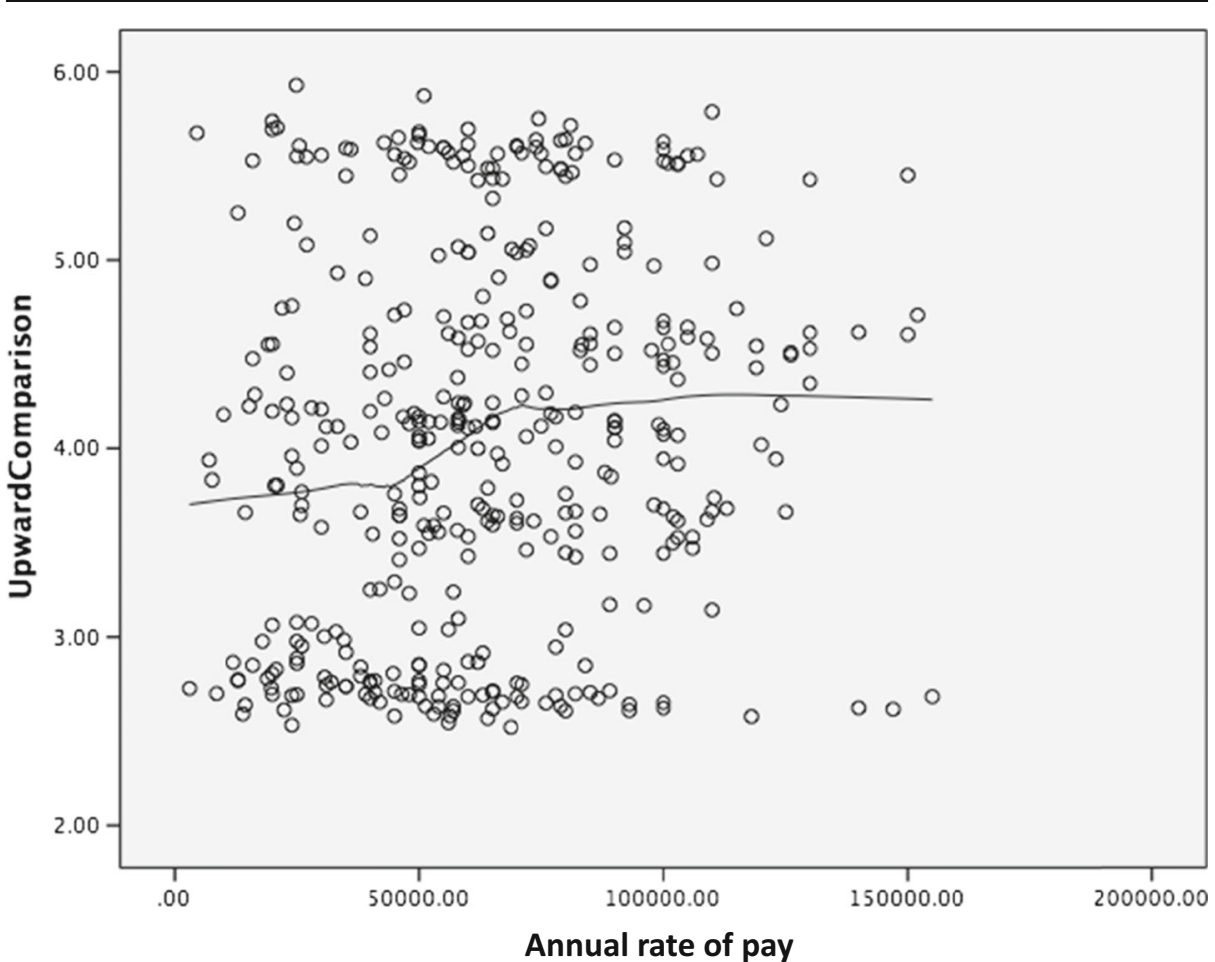

Fig. 7 LOESS curve for upward comparison as a function of annual salary

the continuous S-shaped function). Diminishing returns occur after the waterline is breached. We know that there are some 327 million "working" people who are living under such extremely poor wage barriers (ILO 2016). It remains entirely possible that we will find poverty traps at this poorly understood end of the wage spectrum.

Acknowledgements We wish to thank Massey University for the Vice-Chancellor Discretionary Fund support of this study. Thanks to Associate-Professor Kate Lewis and Ms Lindsay Eastgate for their project assistance. We thank the trade unions, managers and workers who gave their time to help with the design and/or completion of the online and mobile-assisted e-survey, "WageingWell". Thanks to Elon University for helpful student feedback, to Dr Duncan Jackson for insightful and detailed feedback on an earlier version of this paper, Dr Richard B. Fletcher for kindly sharing much expertise on polynomial functions and interpreting plots of regression residuals, and Dr William Cochrane for kindly and expertly suggesting the utilisation of LOESS Curves. We thank our peer reviewers for their expert and constructive guidance on earlier versions of this paper.

\section{References}

Ajzen, I. 2011. Is attitude research incompatible with the compatibility principle? In Most underappreciated: 50 prominent social psychologists talk about hidden gems, ed. R.M. Arkin, 151-154. New York: Oxford University Press.

Ajzen, I., and M. Fishbein. 2005. The influence of attitudes on behaviour. In The handbook of attitudes, ed. D. Albarracín, B.T. Johnson, and M.P. Zanna, 173-221. Mahwah: Erlbaum Publishers.

Alkire, S. 2002. Dimensions of human development. World Development 30: 181-205. 
Alkire, S. 2007. The missing dimensions of poverty data: An introduction. Oxford: Oxford Poverty \& Human Development Initiative (OPHI) Working Paper Series.

Alkire, S. 2008. The capability approach to the quality of life. Oxford: Working Group "Quality of Life".

Anker, R. 2006. Living wages around the world: A new methodology and internationally comparable estimates. International Labour Review 145: 309-338.

Anker, R. 2011. Estimating a living wage: A methodological review. Geneva: ILO.

Arrowsmith, J., and J. Parker. 2013. The meaning of employee engagement for the values and roles of the HRM function. International Journal of Human Resource Management 24: 2692-2712.

Arthur, B. 1989. Competing technologies, increasing returns, and lock-in by historical events. The Economic Journal 99: 116-131.

Avery, M. 2013. Literature review for local polynomial regression. Raleigh: North Carolina State University.

Banerjee, A., and E. Duflo. 2011. Poor economics. New York: Public Affairs.

Bergman, M.E., and V.A. Jean. 2015. Where have all the "workers" gone? A critical analysis of the unrepresentativeness of our samples relative to the labor market in the industrial-organizational psychology literature. Industrial and Organizational Psychology, September, 1-30.

Bosse, D.A., and R.A. Phillips. 2016. Agency theory and bounded self-interest. Academy of Management Review 41: 276-297.

Card, D., and A.B. Krueger. 1994. Minimum wages and employment: A case study of the fast-food industry in New Jersey and Pennsylvania. The American Economic Review 84: 772-793.

Card, D., A. Mas, E. Moretti, and E. Saez. 2012. Inequality at work: The effect of peer salaries on job satisfaction. American Economic Review 102: 2,981-3,003.

Carr, S.C. 2003. Social psychology: Context, communication and culture. Brisbane: Wiley.

Carr, S.C. 2004. Globalization at work: Exploring their combined glocality. Boston: Kluwer-Plenum Academic Publishing.

Carr, S.C. 2010a. Global mobility and local economy: It's work psychology, stupid. In The psychology of global mobility, ed. S.C. Carr, 125-150. New York: Springer.

Carr, S.C. 2010b. The Psychology of global mobility. New York: Springer.

Carr, S.C. 2013. Antipoverty psychology. New York: Springer.

Carr, S.C., and C. Gini. 2011. Project Organizational Gini Coefficient. The Industrial and Organizational Psychologist 49: 102-104.

Carr, S.C., I. McWha, M. MacLachlan, and A. Furnham. 2010. Remuneration discrepancies and poverty reduction: Elephant salaries in the international development parlour. International Journal of Psychology (special section) 45(5): 321-380.

Carr, S.C., E. McAuliffe, and M. MacLachlan. 2014. Servants of empowerment. In Industrial and organizational psychology help the vulnerable: Serving the underserved, ed. W. Reichman, 143-163. Basingstoke: Palgrave-Macmillan.

Carr, S.C., J. Parker, J. Arrowsmith, and P.A. Watters. 2016a. The Living Wage: Theoretical integration and an applied research agenda. International Labour Review 155: 1-24.

Carr, S.C., J. Parker, J. Arrowsmith, P.A. Watters, and H. Jones. 2016b. Anti-poverty living wages: Evidence from New Zealand. Labour and Industry 26: 24-39.

Cleveland, W.S., and S.J. Devlin. 1988. Locally-Weighted Regression: An approach to regression analysis by local fitting. Journal of the American Statistical Association 83: 596-610.

Cobb, J.A. 2016. How firms shape income inequality: Stakeholder power, executive decision making, and the structuring of employment relationships. Academy of Management Review 41: 324-348.

Cohen-Charash, Y., and P.E. Spector. 2001. The role of justice in organizations: A meta-analysis. Organizational Behaviour and Human Decision Processes 86: 278-321.

Colquitt, J.A., D.R. Conlon, M.J. Wesson, C.O.L.H. Porter, and N.K. Yee. 2001. Justice at the millennium: A metaanalytic review of 25 years of organizational justice research. Journal of Applied Psychology 86: 425-445.

Coulson, A.B., and J. Bonner. 2015. Living wage employers: Evidence of UK Business Cases. Strathclyde: University of Strathclyde Business School/Barclays/Living Wage Foundation, UK.

Coyle-Shapiro, J., and M.R. Parzefall. 2008. Psychological contracts. In The Sage handbook of organizational behaviour, ed. C.L. Cooper and J. Barling, 17-34. London: Sage.

Cunniah, D. 2012. Foreword: Social justice and growth - the role of the minimum wage. International Journal of Labor Research 4: 5-6.

Doyle, M.W., and J.E. Stiglitz. 2014. Eliminating extreme inequality: a sustainable development goal, 20152030. Ethics and International Affairs, March 20, Carnegie Council.

Fisher, C. 2010. Happiness at work. International Journal of Management Reviews 12: 384-412.

Folger, R. 1994. Workplace justice and employee worth. Social Justice Research 7: 225-240. 
Fox, J. 2012. The economics of well-being. Harvard Business Review, January, 1-11.

Furnham, A. 2012. Justice at work. In Humanitarian work psychology, ed. S.C. Carr, M. MacLachlan, and A. Furnham, 52-79. Basingstoke: Palgrave-Macmillan.

Galinha, I.C., M.A. Martin, C. Gomes, and S. Oishi. 2016. Criteria for happiness among people living in extreme poverty in Maputo, Mozambique. International Perspectives in Psychology: Research, Practice, Consultation 5: 67-90.

Haar, J.M., and D. Brougham. 2013. An indigenous model of career satisfaction: Exploring the role of workplace cultural wellbeing. Social Indicators Research 110(3): 873-890.

Haar, J.M., M. Russo, A. Sũne, and A. Ollier-Malaterre. 2014. Outcomes of work-life balance on job satisfaction, life satisfaction and mental health: A study across seven countries. Journal of Vocational Behaviour 85: 361-373.

Haar, J., S.C. Carr, J. Parker, and H. Jones .2016. A longitudinal study of fair pay and outcomes in New Zealand: test moderating effects of job status and living wage workplace. British Universities industrial Relations Association Conference, Leeds, UK.

Harris, M.M., F. Anseel, and F. Lievens. 2008. Keeping up with the Joneses: A field study of the relationships among upward, lateral and downward comparison and pay level satisfaction. Journal of Applied Psychology 93: 665-673.

Haslam, A. 2004. Psychology in organizations: The social identity approach. London: Sage.

Hastie, R. 2010. Rational choice in an uncertain world: The psychology of judgement and decision-making, $2 \mathrm{nd}$ ed. Thousand Oaks: Sage.

Haushofer, J. 2013. The psychology of poverty: Evidence from 43 countries. Princeton: Princeton University.

ILO (International Labour Organization). 2013. The World of Work Report 2013: Repairing the economic and social fabric. Geneva: ILO.

ILO (International Labour Organization). 2016. World employment social outlook: Trends 2016. Geneva: ILO.

Jacoby, W.G. 2000. Loess: A nonparametric, graphical tool for depicting relationships between variables. Electoral Studies 19: 577-613.

Jahoda, M. 1982. Employment and unemployment: A social psychological analysis. Cambridge: Cambridge University Press.

Judge, T.A., R.F. Piccolo, N.P. Podsakoff, J.C. Shaw, and B.L. Rich. 2010. The relationship between pay and job satisfaction: A meta-analysis. Journal of Vocational Behaviour 77: 157-167.

Kelly, H. 2014. New Zealand's low wage economy. Wellington: New Zealand Council of Trade Unions.

King, P., and C. Waldegrave. 2012. Report of an investigation into defining a living wage for New Zealand. Wellington: The Living Wage Campaign.

King, P. and C. Waldegrave .2014. Living Wage Aotearoa Movement New Zealand 2014 Update. https://d3n8a8 pro7vhmx.cloudfront.net/nzlivingwage/pages/35/attachments/original/1406711081/Living_Wage_2014_ Report.pdf?1406711081 (accessed 28 November 2014).

Kraay, A., and D. McKenzie. 2014. Do poverty traps exist? Washington, DC: World Bank.

Kuvaas, B. 2006. Work performance, affective commitment and work motivation: The roles of pay administration and pay level. Journal of Organizational Behaviour 27: 365-385.

Latham, G., E.A. Locke, and N.E. Fassina. 2002. The high performance cycle: Standing the test of time. In Psychological management of individual performance, ed. S. Sonnentag, 201-228. New York: Wiley.

Leineweber, C., C. Eib, P. Peristera, and C. Bernhard-Oettel. 2016. The influence of and change in procedural justice on self-rated health trajectories: Swedish Longitudinal Occupational Survey of Health results. Scandinavian Journal of Work, Environment \& Health. doi:10.5271/sjweh.3565.

Lewin, K. 1951. Problems of research in social psychology. In Field theory in social science: Selected theoretical papers, ed. D. Cartwright, 155-169. New York: Harper \& Row.

LWMANZ (Living Wage Aotearoa Movement New Zealand). 2016. Living Wage Aotearoa Movement New Zealand. Wellington: http://www.livingwage.org.nz.

Lyneis, J., and J. Sterman. 2016. How to save a leaky ship: Capability traps and the failure of win-win investments in sustainability and social responsibility. Academy of Management Discoveries 2: 7-32.

MacLachlan, M., S.C. Carr, and E. McAuliffe. 2012. The aid triangle: Recognizing the human dynamics of dominance, justice and identity. New York: Zed Books.

Marsella, A.J. 1994. The measurement of emotional reactions to work: Conceptual, methodological and research issues. Work and Stress 8: 153-176.

Mumford, K., and P.N. Smith. 2012. Peer salaries and employee satisfaction. Bonn: Institute for the Study of Labour.

Niedt, C., G. Ruiters, D. Wise, \& E. Schoenberger .1999. The effects of the living wage in Baltimore. The Johns Hopkins University: Working Paper No. 119. 
Parker, J., C. Yao, J. Arrowsmith, S.C. Carr, L. Eastgate, and H. Jones .2016. Exploring corporate and individual employee rationales for "going living wage". British Universities Industrial Relations Association Conference, Leeds, UK.

Prowse, P., and R. Fells. 2015. The living wage - policy and practice. Annual Conference of the Association of Industrial Relations Academics of Australia and New Zealand, Auckland, February 3-5, Auckland University Business School.

Saner, R., and L. Yiu. 2012. The new diplomacies and humanitarian work psychology. In Humanitarian work psychology, ed. S.C. Carr, M. MacLachlan, and A. Furnham, 129-165. Basingstoke: Palgrave-Macmillan.

Seibert, S.E., G. Wang, and S.H. Courtright. 2011. Antecedents and consequences of psychological and team empowerment in organizations: A meta-analytic review. Journal of Applied Psychology 96: 981-1,003.

Sen, A. 1999. Development as freedom. New York: Random House.

Seth, S., and S. Alkire. 2014. Measuring and decomposing inequality among the multidimensionally poor using ordinal data: a counting approach. Oxford, UK: Oxford Poverty \& Human Development Initiative (OPHI) Working Paper No. 68.

Sirota, D., L.A. Mischkind, and M.I. Meltzer. 2005. The enthusiastic employee. Upper Saddle: Wharton School Publishing.

Smith, N.V. 2012. Equality, justice and identify in an expatriate/local setting: Which human factors enable empowerment of Filipino aid workers? Journal of Pacific Rim Psychology 6: 57-74.

Smith, L. 2015. Reforming the Minimum Wage: Toward a Psychological perspective. American Psychologist 70 : 557-565.

Spector, P.E. 1997. Job satisfaction: Application, assessment, causes and consequences. Thousand Oaks: Sage.

Spreitzer, G.M. 1995. Psychological empowerment in the workplace: Dimensions, measurement and validation. Academy of Management Journal 38: 1,442-1,465.

Stiglitz, J.E. 1976. The Efficiency Wage Hypothesis: Surplus labour and the distribution of income in LDCs. Oxford Economic Papers 28: 185-207.

Stiglitz, J.E. 2002. Employment, social justice and societal well-being. International Labour Review 141: 9-29.

Stringer, C., J. Didham, and P. Theivananthampillai. 2011. Motivation, pay satisfaction, and job satisfaction of front-line employees. Qualitative Research in Accounting \& Management 8: 167-179.

The New Zealand Treasury. 2013. Analysis of the proposed \$18.40 Living Wage. Wellington: The Treasury.

Tourangeau, R., and T. Yan. 2007. Sensitive questions in surveys. Psychological Bulletin 133(5): 859-883.

UN (United Nations). 2015. Open Working Group Proposal for Sustainable Development Goals. New York: UN (https://sustainabledevelopment.un.org/focussdgs.html).

UNDP (United Nations' Development Programme). 2014. Barriers and opportunities at the base of the pyramid: The role of the private sector in inclusive development. Istanbul: Istanbul International Centre for the Private Sector in Development.

Van Knippenburg, D. 2000. Work motivation and performance: A social identity perspective. Applied Psychology 49: 357-371.

Wanous, J.P., A.E. Reichers, and M.J. Hudy. 1997. Overall job satisfaction: How good are single-item measures? Journal of Applied Psychology 82(2): 247-252.

World Bank. 2014. World Development Report 2014 - Risk and opportunity: Overview. Washington, DC: World Bank.

World Bank. 2016. Global monitoring report. Washington, DC: World Bank.

Yao, C., J. Parker, J. Arrowmsith, and S.C. Carr .2016. The living wage and exploring the existence of an income 'tipping point': Qualitative evidence from New Zealand. British Universities Industrial Relations Association Conference, Leeds, UK. 